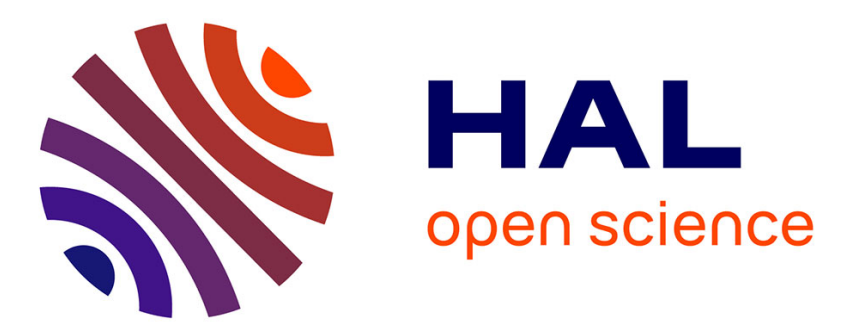

\title{
Triple-quantum correlation NMR experiments in solids using J-couplings
}

\author{
Franck Fayon, Claire Roiland, Lyndon Emsley, Dominique Massiot
}

\section{To cite this version:}

Franck Fayon, Claire Roiland, Lyndon Emsley, Dominique Massiot. Triple-quantum correlation NMR experiments in solids using J-couplings. Journal of Magnetic Resonance, 2006, 179, pp.50-58. 10.1016/j.jmr.2005.11.002 . hal-00016039

\section{HAL Id: hal-00016039 \\ https://hal.science/hal-00016039}

Submitted on 2 Jan 2006

HAL is a multi-disciplinary open access archive for the deposit and dissemination of scientific research documents, whether they are published or not. The documents may come from teaching and research institutions in France or abroad, or from public or private research centers.
L'archive ouverte pluridisciplinaire HAL, est destinée au dépôt et à la diffusion de documents scientifiques de niveau recherche, publiés ou non, émanant des établissements d'enseignement et de recherche français ou étrangers, des laboratoires publics ou privés. 


\title{
Triple-quantum correlation NMR experiments in solids using J-couplings
}

\author{
Franck Fayon $^{\mathrm{a}, *}$, Claire Roiland ${ }^{\mathrm{a}}$, Lyndon Emsley ${ }^{\mathrm{b}}$, Dominique Massiot ${ }^{\mathrm{a}}$ \\ ${ }^{a}$ Centre de Recherches sur les Matériaux à Haute Température, CNRS, 45071 Orléans cedex \\ 2, France. \\ ${ }^{b}$ Laboratoire de Chimie (UMR 5182 CNRS/ENS), Ecole Normale Supérieure de Lyon, 69364 \\ Lyon cedex 7, France.
}

\begin{abstract}
* to whom correspondence should be addressed
email: fayon@cnrs-orleans.fr
\end{abstract}

\begin{abstract}
We show that triple-quantum - single-quantum (TQ-SQ) correlation spectra of crystalline and disordered solids can be obtained under MAS using pulse sequences based on through-bond $J$-couplings. The feasibility of the experiments in coupled spin- $1 / 2$ systems is demonstrated for fully ${ }^{13} \mathrm{C}$-labelled L-alanine and $\mathrm{Pb}_{3} \mathrm{P}_{4} \mathrm{O}_{13}$ crystalline compounds, considered as model three-spin and four-spin systems, respectively. In the case of phosphate glasses, we show that the obtained TQ-SQ correlation spectra provide an improved description of the glass forming network connectivities and of the chain length distribution in the disordered network.
\end{abstract}

\section{Introduction}

Homonuclear double-quantum correlation spectroscopy has been shown to be a valuable tool in solid-state NMR for determining atomic connectivities and studying the structure and dynamic of ordered or disordered materials [1,2]. In this context, various experiments have been developed to obtain two-dimensional (2D) double-quantum -singlequantum (DQ-SQ) correlation spectra of coupled spin-1/2 systems under magic angle spinning (MAS) which is required for enhanced spectral resolution and sensitivity. Many of these methods employ pulse sequences which reintroduce the MAS-averaged through-space homonuclear dipolar interaction, to obtain DQ-SQ correlation spectra which reflect the through-space atomic proximities [3-10]. Alternatively, pulse sequences based on throughbond isotropic $J$-couplings, like the INADEQUATE [11] and refocused INADEQUATE [12] experiments, have also been applied efficiently to obtain through-bond DQ-SQ correlation spectra for large range of materials [12-23].

In the case of inorganic glasses, for which the characterization of medium range order remains challenging, the DQ-SQ correlation experiment allows to improve the structural description obtained from NMR spectroscopy by determining the pairwise connectivities between the basic building units of the disordered network. In phosphate glasses, homonuclear through-bond [22,23] and through-space [24-25] DQ-SQ correlation methods have been applied successfully to probe P-O-P connectivities between the various network former $\mathrm{PO}_{4}$ tetrahedral units $\left(\mathrm{Q}^{\mathrm{n}}\right.$ with $\mathrm{n}$ bridging oxygen atoms). These experiments provide enhanced spectral resolution relative to the conventional MAS spectra allowing the distinction between $\mathrm{Q}^{\mathrm{n}}$ units bonded to different types of $\mathrm{PO}_{4}$ to be made and giving evidence of a chain length distribution in the disordered network [22-25].

Nevertheless, information about longer range order, which could be obtained from a three-spin correlation experiment, remains desirable for a better description of the disordered glassy network. Recently, various dipolar recoupling pulse sequences have been proposed to obtain ${ }^{1} \mathrm{H}$ and ${ }^{13} \mathrm{C}$ homonuclear through-space triple-quantum - single-quantum (TQ-SQ) correlation spectra in solids [26-30]. A modified INADEQUATE experiment was also proposed to record ${ }^{13} \mathrm{C}$ through-bond TQ-SQ correlation spectra of disordered materials [31]. 
In this work, we show that simple pulse sequences, using homonuclear $J$-couplings and based on previously proposed liquid-state NMR sequences [32-34], can be used under MAS conditions to obtain triple-quantum- single-quantum correlation spectra in crystalline and disordered solids. The experiments are demonstrated for ${ }^{13} \mathrm{C}$ and ${ }^{31} \mathrm{P}$ in fully ${ }^{13} \mathrm{C}$-labelled L-alanine and $\mathrm{Pb}_{3} \mathrm{P}_{4} \mathrm{O}_{13}$ crystalline compounds, considered as model three-spin and four-spin systems with linear topology, respectively. In the case of inorganic phosphate glasses, we show that these methods give rise to enhanced spectral resolution relative to DQ-SQ correlation spectra. This provides additional structural information which allows a better description of the P-O-P connectivities and of the chain length distribution in phosphate glasses.

\section{Experimental}

All experiments were performed on a Bruker Advance 300 spectrometer using a $4 \mathrm{~mm}$ CP-MAS probehead operating at Larmor frequencies of $75.5,121.5$, and $300.1 \mathrm{MHz}$ for ${ }^{13} \mathrm{C}$, ${ }^{13} \mathrm{P}$ and ${ }^{1} \mathrm{H}$, respectively. The spinning frequency was $14 \mathrm{kHz}$ for all experiments. For the ${ }^{13} \mathrm{C}$ experiments, a ramped cross polarization [35] with a contact time of $1 \mathrm{~ms}$ was used and ${ }^{1} \mathrm{H}$ decoupling was achieved using the SPINAL64 sequence [36] with a ${ }^{1} \mathrm{H}$ nutation frequency of $70 \mathrm{kHz}$. The ${ }^{13} \mathrm{C}$ pulses used for the excitation and reconversion of triple-quantum (TQ) coherences employed a nutation frequency $57 \mathrm{kHz}$. For the ${ }^{31} \mathrm{P}$ experiments, the ${ }^{31} \mathrm{P}$ nutation frequency was $96 \mathrm{kHz}$. Two dimensional pure absorption phase spectra were obtained using the States method [37]. The phases of the pulses used for TQ excitation were cycled in steps of $60^{\circ}$. For the experiments using a $\mathrm{z}$-filter, the phase of the final $90^{\circ}$ pulse was cycled in steps of $90^{\circ}$. The $t_{1}$ time increment and the $\tau / 2$ delays in the TQ excitation and reconversion periods were synchronized with the rotor period. ${ }^{13} \mathrm{C}$ and ${ }^{31} \mathrm{P}$ chemical shifts were referenced relative to $\mathrm{Si}\left(\mathrm{CH}_{3}\right)_{4}$ and a $85 \% \mathrm{H}_{3} \mathrm{PO}_{4}$ solution, respectively. The pulse programs and phase cycles used to record the spectra are available upon request from the authors.

\section{Results and discussion}

\subsection{Pulse sequences}

The different pulse sequences used to record triple-quantum - single-quantum correlation MAS spectra of spin $1 / 2$ nuclei using $J$-couplings are shown in figure 1 . They are analogous to those previously used in liquid-state NMR [32-34], except for the sample spinning, the ${ }^{1} \mathrm{H}$ decoupling and cross-polarization periods. The first pulse sequence, shown in figure 1a, has been proposed for the excitation of odd coherence orders in homonuclear $\mathrm{AX}_{\mathrm{n}}$ spin systems with $\mathrm{n}$ even and has been shown to yield an efficient triple-quantum excitation in a three-spin system with the $\mathrm{AX}_{2}$ topology [32]. It uses two rotor-synchronized spin-echo periods for the excitation of triple-quantum coherences. In this context, fast magic angle spinning is used to average the homonuclear dipolar couplings and chemical shift anisotropies (CSA). The evolution during the two spin echoes, which refocus the isotropic chemical shifts, is thus only due to the homonuclear $J$-coupling interactions. The ${ }^{13} \mathrm{C}$ transverse magnetization along the y axis is generated by cross-polarization from ${ }^{1} \mathrm{H}$ or by a $90^{\circ}$ pulse. After a first evolution period under homonuclear isotropic $J$-couplings during a delay $\tau_{1}$, a $90^{\circ}$ pulse along the $\mathrm{x}$ axis generates a mixture of zero-quantum and doublequantum coherences. The zero-quantum and double-quantum coherences evolve under homonuclear $J$-couplings during a second evolution period of duration $\tau_{2}$. After this second $\tau_{2}$ delay, a $90^{\circ}$ pulse along the $\mathrm{x}$ axis creates the ${ }^{13} \mathrm{C}$ triple-quantum (TQ) coherences which evolve at the sum of the isotropic shifts of the three coupled spins during the incremented time $t_{1}$. The TQ coherences are converted back into longitudinal magnetization by a reconversion sequence similar to the excitation sequence with pulses and delays applied in reversed order. An additional z-filter delay is applied before the final $90^{\circ}$ read pulse to purge 
anti-phase transverse coherences and to observe in-phase line shapes. The second pulse sequence, shown in figure $1 \mathrm{~b}$, uses a single rotor-synchronized evolution period under homonuclear $J$-coupling interactions for the excitation of triple-quantum coherences $[33,34]$. As previously, the ${ }^{13} \mathrm{C}$ transverse magnetization along the $\mathrm{y}$ axis, generated by crosspolarization from ${ }^{1} \mathrm{H}$, evolves under homonuclear isotropic $J$-couplings during a delay $\tau$. After the delay $\tau$, the ${ }^{13} \mathrm{C}$ TQ coherences are directly created by a $90^{\circ}$ pulse along the y axis. The reconversion of TQ coherences into longitudinal magnetization is achieved by a reconversion sequence which acts in a similar manner to the excitation sequence and a z-filter delay is introduced before the final $90^{\circ}$ read pulse to detect in-phase signals. In this experiment, the excitation and reconversion of TQ coherences require an evolution under two $J$-couplings simultaneously during the delay $\tau$. For a linear AMX three-spin systems (with $J_{A X}=0$ ), the efficiency of the experiment is therefore restricted to the central nucleus [33].

For the two pulse sequences, the triple-quantum filtering (TQF) efficiencies expected from standard product operator algebra [38] for a AMX three-spin system with a liquid-like $J$ coupling Hamiltionan (in the weak coupling approximation and neglecting relaxation effects) are presented in the appendix. In the case of a linear AMX three-spin system $\left(J_{\mathrm{AX}}=0\right)$, that will be considered in the following, similar calculations lead to the expressions:

For the experiment in figure $1 \mathrm{a}$,

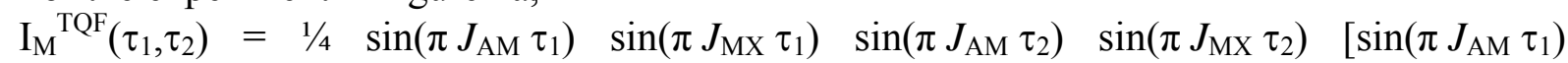

$\left.\sin \left(\pi J_{\mathrm{MX}} \tau_{2}\right)+\sin \left(\pi J_{\mathrm{MX}} \tau_{1}\right) \sin \left(\pi J_{\mathrm{AM}} \tau_{2}\right)\left(1+\sin \left(\pi J_{\mathrm{AM}} \tau_{1}\right) \sin \left(\pi J_{\mathrm{MX}} \tau_{2}\right)\right)\right]$

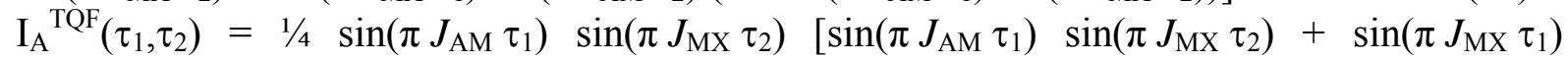

$\left.\sin \left(\pi J_{\mathrm{AM}} \tau_{2}\right)\left(1+\sin \left(\pi J_{\mathrm{AM}} \tau_{1}\right) \sin \left(\pi J_{\mathrm{MX}} \tau_{2}\right)\right)\right]$

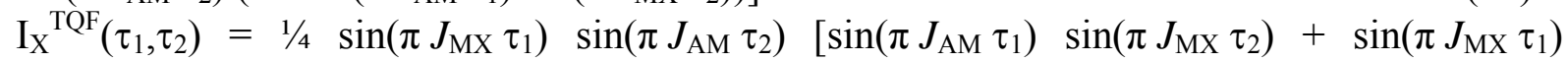

$\left.\sin \left(\pi J_{\mathrm{AM}} \tau_{2}\right)\left(1+\sin \left(\pi J_{\mathrm{AM}} \tau_{1}\right) \sin \left(\pi J_{\mathrm{MX}} \tau_{2}\right)\right)\right]$.

For $\tau_{1}=\tau_{2}=\tau$, this gives:

$\mathrm{I}_{\mathrm{M}}^{\mathrm{TQF}}(\tau)=1 / 4 \sin ^{3}\left(\pi J_{\mathrm{AM}} \tau\right) \sin ^{3}\left(\pi J_{\mathrm{MX}} \tau\right)\left[2+\sin \left(\pi J_{\mathrm{AM}} \tau\right) \sin \left(\pi J_{\mathrm{MX}} \tau\right)\right]$

$\mathrm{I}_{\mathrm{A}}^{\mathrm{TQF}}(\tau)=\mathrm{I}_{\mathrm{X}}^{\mathrm{TQF}}(\tau)=1 / 4 \sin ^{2}\left(\pi J_{\mathrm{AM}} \tau\right) \sin ^{2}\left(\pi J_{\mathrm{MX}} \tau\right)\left[2+\sin \left(\pi J_{\mathrm{AM}} \tau\right) \sin \left(\pi J_{\mathrm{MX}} \tau\right)\right]$.

For the experiment in figure $1 \mathrm{~b}$,

$\mathrm{I}_{\mathrm{M}}^{\mathrm{TQF}}(\tau)=1 / 4 \sin ^{2}\left(\pi J_{\mathrm{AM}} \tau\right) \sin ^{2}\left(\pi J_{\mathrm{MX}} \tau\right)$

$\mathrm{I}_{\mathrm{A}}^{\mathrm{TQF}}(\tau)=\mathrm{I}_{\mathrm{X}}^{\mathrm{TQF}}(\tau)=0$.

According to these equations, the maximum TQF efficiencies of the two experiments strongly depend on the two $J$-coupling values of the AMX spin system. In the general case $\left(J_{\mathrm{AM}} \neq\right.$ $\left.J_{\mathrm{MX}}\right)$, there is no trivial solution for the maximum TQF efficiencies and the corresponding values of delay in the rotor-synchronized spin-echo period(s). In the simple case where the two coupling are equal $\left(J_{\mathrm{AM}}=J_{\mathrm{MX}}=J\right)$, the maximum TQF efficiency of the experiment in Fig. 1a reaches $75 \%$ for the three nuclei at $\tau_{1}=\tau_{2}=1 /(2 J)$. For the same case, a maximum TQF efficiency of $25 \%$ for the central nucleus is achieved at $\tau=1 /(2 J)$ using the pulse sequence in Fig. 1b.

\subsection{Application to a linear three-spin system}

\subsubsection{Two-dimensional correlation spectra}

The triple-quantum - single-quantum correlation spectra of a sample of fully ${ }^{13} \mathrm{C}$ labelled L-alanine, obtained using the pulse sequences of Fig. $1 \mathrm{a}$ and $1 \mathrm{~b}$ for a spinning frequency of $14 \mathrm{kHz}$ and a magnetic field of $7.0 \mathrm{~T}$, are shown in figure $2 \mathrm{a}$ and $2 \mathrm{~b}$, respectively. Considering only the homonuclear $J$-coupling interactions, this sample represents a linear AMX three-spin system for which a single TQ coherence is expected. The 2D TQ-SQ correlation spectrum obtained with the sequence of Fig. 1a shows a single TQ resonance in the $\omega_{1}$ dimension correlated to the three individual resonances of the spin system in the single-quantum dimension. In contrast, the 2D TQ-SQ correlation spectrum obtained 
with the sequence of Fig. 1b shows a single correlation peak between the TQ resonance and the $\mathrm{C}^{\alpha}$ resonance. This experiment allows the spectral edition of the central nucleus of the linear AMX spin triplet and the $\mathrm{CO}$ and $\mathrm{C}^{\beta}$ resonances are missing from the spectrum, as expected for a linear three-spin topology. The information about the coupling partners is directly obtained from the TQ frequency which corresponds to the sum of the isotropic shifts of the three coupled spins. It should be noted that, for a three-spin system, the triple-quantum coherence is not affected by the $J$-couplings between the three nuclei. Consequently, the $J$ multiplets, which are clearly resolved for the $\mathrm{CO}$ and the $\mathrm{C}^{\beta}$ resonances in the single quantum-dimension, are not observed in the triple-quantum dimension of the $2 \mathrm{D}$ correlation spectra of Fig. 2a and $2 b$.

\subsubsection{Triple-quantum filtering efficiency}

Figure 3 shows numerical simulations of the triple-quantum filtering efficiency as a function of the delay $\tau$ (with $\tau=\tau_{1}=\tau_{2}$ ) for fully ${ }^{13} \mathrm{C}$-labelled L-alanine, at different spinning frequencies in a magnetic field of 7.0 T. The simulations, which take in account the effect of the CSA and homonuclear dipolar interactions in addition to the $J$-couplings, were performed using the SIMPSON software [39] with the parameters given in [40,41] and neglecting both ${ }^{1} \mathrm{H}-{ }^{13} \mathrm{C}$ dipolar couplings and relaxation effects. The TQF efficiency expected from standard product operator algebra [38] for a liquid-like J-coupling Hamiltionan (Eq. [2a-b] and Eq. [3ab]) is also depicted in figure 3. For a moderate spinning frequency of $7 \mathrm{kHz}$, the numerical simulations show that the TQF efficiency of the experiments is slightly affected by the homonuclear dipolar and CSA interactions. We see that the main behavior (for times up to $10 \mathrm{~ms}$ ) is largely as expected for a $J$ coupling, but that at longer times dipolar induced behavior is observed. This is reminiscent of the observations in Ref. [42] and this could lead to artefacts in the spectrum with the sequence of figure $1 \mathrm{~b}$, where a reconversion of the TQ coherence into the $\mathrm{CO}$ and $\mathrm{C}^{\beta} \mathrm{SQ}$ resonances is observed (see figure 3e). Nevertheless, for a spinning frequency of $14 \mathrm{kHz}$, the oscillating behaviour is dominated by the $J$-couplings for the range of delay $\tau$ investigated and experimentally accessible, the anisotropic interactions resulting in a weak decrease of the TQF efficiency. At very fast spinning frequencies (34 $\mathrm{kHz}$ ), the simulations mimic almost perfectly the expected behaviour for liquid-like $J$ couplings. This suggests that these experiments can be used to probe through-bond connectivities under fast and very fast MAS conditions. However, the effect of CSA and dipolar interactions may be more important in other specific situations, which were not considered here. In particular, it was recently shown for spin $1 / 2$ pairs satisfying a rotational resonance condition that the rotor-synchronised spin-echo modulation is strongly influenced by the dipolar interaction $(\mathrm{n} \neq 0$ rotational resonance) or by a dipolar-CSA cross term $(n=0$ rotational resonance between two coupled nuclei with identical isotropic shift and different CSA principal values or orientations) which depends on the spinning frequency [42]. For these specific cases, it was also shown that correlation peaks can be observed in doublequantum - single-quantum correlation spectra obtained with the refocused INADEQUATE sequence even in the absence of $J$-coupling [43].

The experimental ${ }^{13} \mathrm{C}$ TQF efficiencies for fully ${ }^{13} \mathrm{C}$-labelled L-alanine obtained at a spinning rate of $14 \mathrm{kHz}$ in a magnetic field of $7.0 \mathrm{~T}$ are shown in figure $4(\mathrm{a}-\mathrm{b})$. For the experiment of figure 1a, maximum TQF efficiencies of about $6.5,3.0$ and $1.8 \%$ were obtained for the $\mathrm{CO}, \mathrm{C}^{\alpha}$ and $\mathrm{C}^{\beta}$ resonances, respectively, corresponding to an efficiency of $3.4 \%$ for the total ${ }^{13} \mathrm{C}$ magnetization. For the sequence of figure $1 \mathrm{~b}$, the maximum TQF efficiency reaches about $4 \%$ for the $\mathrm{C}^{\alpha}$ resonance. These experimental efficiencies are significantly weaker than those expected from the simulations due to the dephasing processes occurring during the rotor-synchronized spin echo period(s) used for the excitation and reconversion of TQ coherences. To illustrate this effect, the theoretical curves (Eq. [2a-b], Eq. 
[3a]) including damping with a phenomenological time constant $\mathrm{T}$ of $20 \mathrm{~ms}$ are also shown in Fig. 4. Moreover, other experimental factors like RF field inhomogeneities and imperfect ${ }^{1} \mathrm{H}$ decoupling also lead to a decrease of the TQF efficiency. It should be mentioned that these TQF efficiencies are weaker than those obtained using various homonuclear dipolar recoupling methods [27-30] which are of about 4 [27], 9 [28] and 11\% [29,30] for the total ${ }^{13} \mathrm{C}$ magnetization on a full rotor of L-alanine. However, since the sensitivity of experiments of Fig. 1a and $1 \mathrm{~b}$ is mostly affected by dephasing effects, it will directly benefit of the increased efficiency of heteronuclear decoupling sequences which enhance the transverse coherence lifetimes [16,44]. For example, the optimised CM decoupling sequence [45] has been shown to provide coherence lifetimes about a factor 2 longer than unoptimised TPPM [46] or SPINAL-64 [36] sequences, leading to significant increase of the sensitivity of DQSQ correlation spectra recorded with the refocused INADEQUATE sequence [16]. As mentioned previously [32], the TQF efficiency could also be improved using composite pulses to compensate the effect of RF field inhomogeneities.

\subsection{Application to a linear four-spin system}

Figure 5 shows the experimental ${ }^{31} \mathrm{P}$ TQ-SQ correlation spectra of a $\mathrm{Pb}_{3} \mathrm{P}_{4} \mathrm{O}_{13}$ crystalline sample obtained at a magnetic field of $7.0 \mathrm{~T}$ and a spinning frequency of $14 \mathrm{kHz}$ using the sequences of Fig. $1 \mathrm{a}$ and $1 \mathrm{~b}$ (replacing the cross polarization step by a strong $90^{\circ}$ pulse and omitting ${ }^{1} \mathrm{H}$ decoupling). The structure of crystalline $\mathrm{Pb}_{3} \mathrm{P}_{4} \mathrm{O}_{13}$ contains four crystallographic non-equivalent phosphorous sites forming a linear tetrameric $\left[\mathrm{P}_{4} \mathrm{O}_{13}\right]^{6-}$ anion with two $\mathrm{Q}^{1}$ end-chain units and two $\mathrm{Q}^{2}$ middle-chain groups [47]. Considering only ${ }^{2} J\left({ }^{31} \mathrm{P}-\mathrm{O}\right.$ ${ }^{31} \mathrm{P}$ ) couplings, this sample represents a linear four-spin system. As expected, the $2 \mathrm{D}$ spectrum recorded with the sequence of Fig. 1a exhibits two triple-quantum resonances correlated with the three individual resonances of the two $\mathrm{Q}^{1}-\mathrm{Q}^{2}-\mathrm{Q}^{2}$ spin-triplets and reflects the P-O-P connectivities of the linear tetrameric anion. For the experiment of Fig. 1b, the two TQ resonances show strong correlation peaks with the resonances of the two $\mathrm{Q}^{2}$ middle-chain groups. In this case, the $\mathrm{Q}_{1}$ resonances also show a correlation peak of very weak intensity, which is not expected assuming a coherence transfer only mediated by liquid-like $J$-couplings. SIMPSON numerical simulations (not shown) performed for different MAS spinning frequencies suggest that these weak-intensity cross-peaks are due to the presence of homonuclear dipolar and CSA interactions (this peak should disappear at higher spinning frequencies). It should be noted that the ${ }^{2} J(\mathrm{P}-\mathrm{OP})$ couplings are significantly smaller than the ${ }^{31} \mathrm{P}$ line widths $(\sim 80 \mathrm{~Hz})$ and are not resolved in the 2D correlation and 1D MAS spectra. However, this does not affect the sensitivity of these experiments since in-phase signals are detected. For this sample, the experimental TQF efficiencies are relatively weak due to the dephasing processes during the TQ excitation and reconversion periods. Experimentally, maximum TQF efficiencies of about 3.0 and $1.0 \%$ for the two $\mathrm{Q}^{1}$ and the two $\mathrm{Q}^{2}$ resonances were achieved using the experiment in Fig. 1a with the delays $\tau_{1}=16 \mathrm{~ms}$ and $\tau_{2}=10 \mathrm{~ms}$ in the two consecutive spin-echo periods used both for the TQ excitation and reconversion. These delays were adjusted empirically to provide the best efficiency. For the experiment in Fig. 1b, a maximum TQF efficiency of about $3.8 \%$ for the two $\mathrm{Q}^{2}$ resonances was obtained using a delay $\tau$ of $18 \mathrm{~ms}$.

\subsection{Application to phosphate glass}

The application of these experiments in the case of disordered solids is demonstrated in figure 6, which shows the TQ-SQ correlation spectra of a lead phosphate glass with composition $(\mathrm{PbO})_{0.61}\left(\mathrm{P}_{2} \mathrm{O}_{5}\right)_{0.39}$. In this case, two variants of the pulse sequences, depicted in figure $1 \mathrm{c}$ and $1 \mathrm{~d}$, were employed. For disordered solids showing a large distribution of isotropic chemical shifts relative to the $J$-coupling values, antiphase line shapes are not 
detected due to cancellation effects [34]. In this case, the TQ coherences are directly converted into transverse magnetization by omitting the last $90^{\circ}$ pulse of the reconversion sequence (figures $1 \mathrm{~b}$ and $1 \mathrm{~d}$ ). This enables the acquisition of a full echo signal, as used in DAS [48] and MQMAS [49] experiments, which results in unambiguous phasing of the pure absorption mode $2 \mathrm{D}$ spectrum and improving the signal to noise ratio by up to a factor of $2^{1 / 2}$. The ${ }^{31} \mathrm{P}$ MAS spectrum of the $(\mathrm{PbO})_{0.61}\left(\mathrm{P}_{2} \mathrm{O}_{5}\right)_{0.39}$ glass (shown in Fig. 7a) exhibits two broad isotropic resonances assigned to $\mathrm{Q}^{1}$ end-chain sites and $\mathrm{Q}^{2}$ middle-chain groups, according to the ${ }^{31} \mathrm{P}$ isotropic chemical shift ranges and the $J$-multipet structures evidenced from a spin echo MAS experiment [23]. For each $\mathrm{Q}^{\mathrm{n}}$ unit, the broadening of the resonance comes from a large distribution of ${ }^{31} \mathrm{P}$ chemical shifts reflecting the structural disorder in the glass. As shown in figure $6 \mathrm{~b}$, the TQ-SQ correlation spectra of the glass obtained using the sequence in Fig. 1a allows to resolve three broad TQ resonances. One of the three TQ resonances shows a single correlation peak with the SQ $\mathrm{Q}^{2}$ resonance (along the TQ-SQ diagonal of the spectrum) and is characteristic of a spin-triplet involving 3 coupled $Q^{2}$ units $\left(Q_{2}-Q_{2}-Q_{2}\right)$. The remaining TQ resonances, centered at about -57 and $-42 \mathrm{ppm}$, exhibits two cross-correlation peaks with both the $\mathrm{Q}^{1}$ and $\mathrm{Q}^{2}$ resonances in the $\mathrm{SQ}$ dimension and can be attributed to $\mathrm{Q}^{2}-\mathrm{Q}^{2}-\mathrm{Q}^{1}$ and $\mathrm{Q}^{1}$ $\mathrm{Q}^{2}-\mathrm{Q}^{1}$ triplets according to their TQ frequencies. In the spectrum recorded with the sequence of Fig. 1c, the three TQ resonances associated to the three types of spin-triplets exhibit intense correlation peaks with the $\mathrm{Q}^{2} \mathrm{SQ}$ resonance. Additional correlation peaks of very weak intensity are also observed for the $\mathrm{Q}^{1}$ resonances, as in the case of the crystalline $\mathrm{Pb}_{3} \mathrm{P}_{4} \mathrm{O}_{13}$ sample. These TQ-SQ correlation spectra therefore reveal the P-O-P connectivities involved in trimers $Q^{1}-Q^{2}-Q^{1}$ and in longer phosphate chains containing at least $4\left(Q^{2}-Q^{2}-Q^{1}\right)$ or $5\left(Q^{2}-\right.$ $\left.\mathrm{Q}^{2}-\mathrm{Q}^{2}\right) \mathrm{PO}_{4}$ tetrahedra, clearly indicating the presence of a chain length distribution in the glass network. It should be noted that the resonances of $\mathrm{P}_{2} \mathrm{O}_{7}$ dimers are filtered out of these through-bond TQ-SQ correlation spectra. Therefore, complementary information about the chain length statistic can be obtained form through-bond DQ-SQ correlation experiments which have been previously used to evidence unambiguously the $\mathrm{Q}_{1}-\mathrm{Q}_{1}$ connectivities characteristic of $\mathrm{P}_{2} \mathrm{O}_{7}$ groups in a glass of similar composition [22]. A quantitative interpretation of the different TQ resonances of the glass would be very difficult due to a complex interplay amongst distributions of J-couplings, relaxation times and isotropic chemical shifts that will affect the efficiency of the experiments. However, a notable feature in the TQ-SQ spectra is that the three correlation peaks of the $Q^{2}$ resonance appear at significantly different frequencies in the SQ dimension and show Gaussian line shapes. This shows that the ${ }^{31} \mathrm{P}$ isotropic chemical shift is sensitive to the $\mathrm{Q}^{\mathrm{n}}$ type of the bonded adjacent tetrahedra, corresponding to structural changes in the fourth coordination sphere of phosphorus. In contrast, the two correlation peaks of the $\mathrm{Q}^{1}$ resonance (associated to the $\mathrm{Q}^{1}$ $\mathrm{Q}^{2}-\mathrm{Q}^{1}$ and $\mathrm{Q}^{1}-\mathrm{Q}^{2}-\mathrm{Q}^{2}$ triplets) occur at a similar $\mathrm{SQ}$ frequency, indicating that longer range structural modifications do not significantly affect the ${ }^{31} \mathrm{P}$ chemical shift. The small ${ }^{31} \mathrm{P}$ chemical shift variations (of about $1.5 \mathrm{ppm}$ ) as a function of the nature the linked tetrahedra were first observed in DQ-SQ correlation spectra [24-25] and allow an improved description of the $\mathrm{Q}^{\mathrm{n}}$ network forming units. This is illustrated in figure $7 \mathrm{~b}$, which shows the projection of the spin-triplet correlation peaks along the SQ dimension of the TQ-SQ spectra and the projection of the $\mathrm{Q}^{1}-\mathrm{Q}^{1}$ correlation peak along the SQ dimension of a DQ-SQ spectrum obtained with the refocused INADEQUATE sequence. TQ-SQ trough-bond correlation spectroscopy appears therefore a complementary tool to conventional DQ-SQ correlation methods, allowing a detailed characterization of the different $\mathrm{Q}^{\mathrm{n}}$ tetrahedra forming the disordered network and of the chain length statistic in phosphate glasses with high modifier content, i.e. containing short chains.

\section{Conclusion}


In this work, we have shown that simple pulse sequences, based on scalar $J$-couplings and previously developed for liquid-state NMR, can be applied under MAS condition to obtain homonuclear triple-quantum - single-quantum correlation spectra of crystalline and disordered solids. As demonstrated for model three-spin and four-spin systems with a linear topology, the obtained TQ-SQ correlation spectra reflect the expected through-bond connectivities. In the case of phosphate glasses, we show that these methods can be efficiently applied to obtain TQ-SQ correlation spectra which provide an improved description of the P$\mathrm{O}-\mathrm{P}$ connectivities and of the chain length distribution in the disordered phosphate network.

\section{Appendix}

Here, we give the triple-quantum filtering efficiencies of the two pulse sequences expected from standard product operator algebra for a AMX three-spin system with a liquid-like $J$ coupling Hamiltionan (in the weak coupling approximation and neglecting relaxation effects). For the experiment in figure $1 \mathrm{a}$ :

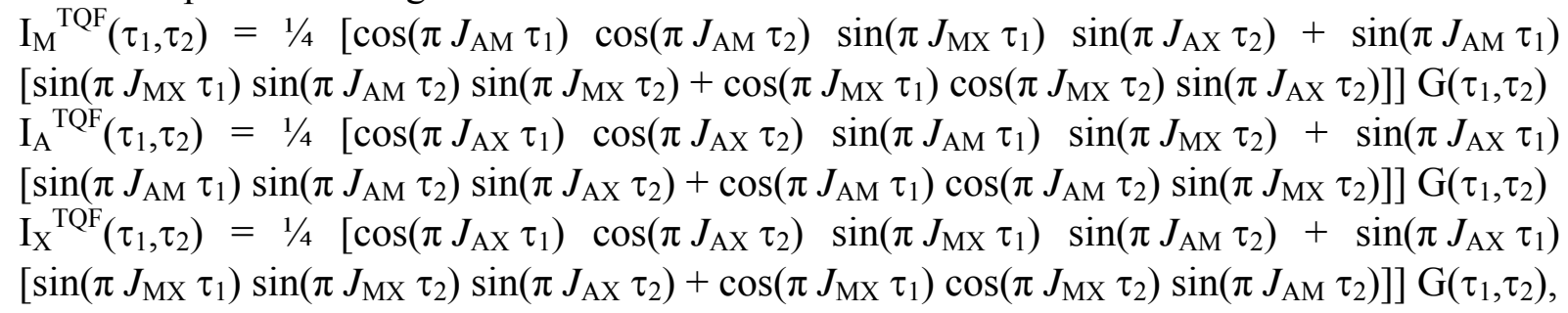

with $\mathrm{G}\left(\tau_{1}, \tau_{2}\right)=\left[\begin{array}{llll}\cos \left(\pi J_{\mathrm{AM}} \tau_{1}\right) & \cos \left(\pi J_{\mathrm{AM}} \tau_{2}\right) & \sin \left(\pi J_{\mathrm{AX}} \tau_{1}\right) & \sin \left(\pi J_{\mathrm{MX}} \tau_{2}\right)+\sin \left(\pi J_{\mathrm{AM}} \tau_{1}\right)\end{array}\right.$ $\sin \left(\pi J_{\mathrm{MX}} \tau_{1}\right) \quad \sin \left(\pi J_{\mathrm{AM}} \tau_{2}\right) \quad \sin \left(\pi J_{\mathrm{MX}} \tau_{2}\right)+\cos \left(\pi J_{\mathrm{AX}} \tau_{1}\right) \quad \cos \left(\pi J_{\mathrm{AX}} \tau_{2}\right) \quad\left[\sin \left(\pi J_{\mathrm{MX}} \tau_{1}\right)\right.$ $\left.\sin \left(\pi J_{\mathrm{AM}} \tau_{2}\right)+\sin \left(\pi J_{\mathrm{AM}} \tau_{1}\right) \sin \left(\pi J_{\mathrm{MX}} \tau_{2}\right)\right]+\cos \left(\pi J_{\mathrm{AM}} \tau_{1}\right) \cos \left(\pi J_{\mathrm{AM}} \tau_{2}\right) \sin \left(\pi J_{\mathrm{MX}} \tau_{1}\right)$

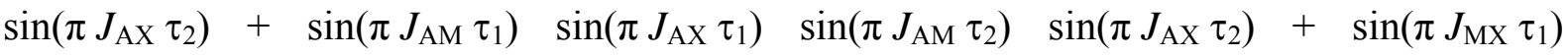
$\sin \left(\pi J_{\mathrm{AX}} \tau_{1}\right) \quad \sin \left(\pi J_{\mathrm{MX}} \tau_{2}\right) \quad \sin \left(\pi J_{\mathrm{AX}} \tau_{2}\right) \quad+\cos \left(\pi J_{\mathrm{MX}} \tau_{1}\right) \quad \cos \left(\pi J_{\mathrm{MX}} \tau_{2}\right) \quad\left[\sin \left(\pi J_{\mathrm{AX}} \tau_{1}\right)\right.$ $\left.\left.\sin \left(\pi J_{\mathrm{AM}} \tau_{2}\right)+\sin \left(\pi J_{\mathrm{AM}} \tau_{1}\right) \sin \left(\pi J_{\mathrm{AX}} \tau_{2}\right)\right]\right]$.

For the experiment in figure $1 \mathrm{~b}$ :

$\mathrm{I}_{\mathrm{M}}{ }^{\mathrm{TQF}}(\tau)=\sin \left(\pi J_{\mathrm{AM}} \tau\right) \sin \left(\pi J_{\mathrm{MX}} \tau\right)\left[\sin \left(\pi J_{\mathrm{MX}} \tau\right) \sin \left(\pi J_{\mathrm{AX}} \tau\right)+\sin \left(\pi J_{\mathrm{AM}} \tau\right)\left[\sin \left(\pi J_{\mathrm{MX}} \tau\right)+\right.\right.$ $\left.\left.\sin \left(\pi J_{\mathrm{AX}} \tau\right)\right]\right]$

$\mathrm{I}_{\mathrm{A}}^{\mathrm{TQF}}(\tau)=\sin \left(\pi J_{\mathrm{AM}} \tau\right) \sin \left(\pi J_{\mathrm{AX}} \tau\right)\left[\sin \left(\pi J_{\mathrm{MX}} \tau\right) \sin \left(\pi J_{\mathrm{AX}} \tau\right)+\sin \left(\pi J_{\mathrm{AM}} \tau\right)\left[\sin \left(\pi J_{\mathrm{MX}} \tau\right)+\right.\right.$ $\left.\left.\sin \left(\pi J_{\mathrm{AX}} \tau\right)\right]\right]$

$\mathrm{I}_{\mathrm{X}}^{\mathrm{TQF}}(\tau)=\sin \left(\pi J_{\mathrm{MX}} \tau\right) \sin \left(\pi J_{\mathrm{AX}} \tau\right)\left[\sin \left(\pi J_{\mathrm{MX}} \tau\right) \sin \left(\pi J_{\mathrm{AX}} \tau\right)+\sin \left(\pi J_{\mathrm{AM}} \tau\right)\left[\sin \left(\pi J_{\mathrm{MX}} \tau\right)+\right.\right.$ $\left.\left.\sin \left(\pi J_{\mathrm{AX}} \tau\right)\right]\right]$.

\section{References}

[1] S.P. Brown, H.W. Spiess, Advanced solid-state NMR methods for the elucidation of structure and dynamics of molecular, macromolecular, and supramolecular systems, Chem. Rev. 101 (2001) 4125-4155.

[2] M. Baldus, Correlation experiments for assignment and structure elucidation of immobilized polypeptides under magic angle spinning, Prog. NMR Spectrosc. 41 (2002) 1-47.

[3] R. Tycko, G. Dabbagh, Double-quantum filtering in magic-angle-spinning NMR spectroscopy: An approach to spectral simplification and molecular structure determination, J. Am. Chem. Soc. 113 (1991) 9444-9448.

[4] H. Geen, J.J. Titman, J. Gottwald, H.W. Spiess, Solid-state proton multiple-quantum NMR spectroscopy with fast magic angle spinning, Chem. Phys. Letters 227 (1994) 79-86. 
[5] Y.K. Lee, N.D. Kurur, M. Elm, O.G. Johannessen, N.C. Nielsen, M.H. Levitt, Efficient dipolar recoupling in the NMR of rotating solids. A sevenfold symmetric radiofrequency pulse sequence, Chem. Phys. Letters 242 (1995) 304-309.

[6] M. Feike, D.E. Demco, R. Graf, J. Gottwald, S. Hafner, H.W. Spiess, Broadband Multiple-Quantum NMR Spectroscopy, J. Magn. Reson. Ser. A 122 (1996) 214-221.

[7] M. Hohwy, H.J. Jakobsen, M. Edén, M.H. Levitt, N.C. Nielsen, Broadband dipolar recoupling in the nuclear magnetic resonance of rotating solids: A compensated $\mathrm{C} 7$ pulse sequence, J. Chem. Phys. 108 (1998) 2686-2694.

[8] M. Hohwy, C.M. Rienstra, C.P. Jaroniec, R.G. Griffin, Fivefold symmetric homonuclear dipolar recoupling in rotating solids: Application to double quantum spectroscopy, J. Chem. Phys. 110 (1999) 7983-7992.

[9] R. Verel, M. Ernst, B.H. Meier, Adiabatic dipolar recoupling in solid-state NMR: The DREAM scheme, J. Magn. Reson. 150 (2001) 81-99.

[10] S.P. Brown, A. Lesage, B. Elena, L. Emsley, Probing proton-proton proximities in the solid state: High-resolution two-dimensional ${ }^{1} \mathrm{H}-{ }^{1} \mathrm{H}$ double-quantum CRAMPS NMR spectroscopy, J. Am. Chem. Soc. 126 (2004) 13230-13231.

[11] A. Bax, R. Freeman, T.A. Frenkiel, An NMR technique for tracing out the carbon skeleton of an organic molecule, J. Am. Chem. Soc. 103 (1981) 2102-2104.

[12] A. Lesage, M. Bardet, L. Emsley, Through-bond carbon-carbon connectivities in disordered solids by NMR, J. Am. Chem. Soc. 121 (1999) 10987-10993.

[13] C.A. Fyfe, Y. Feng, H. Gies, H. Grondey, G.T. Kokotailo, Natural-abundance twodimensional solid-state silicon-29 NMR investigations of three-dimensional lattice connectivities in zeolite structures, J. Am. Chem. Soc. 112 (1990) 3264-3270.

[14] A. Lesage, C. Auger, S. Caldarelli, L. Emsley, Determination of through-bond carboncarbon connectivities in solid-state NMR using the INADEQUATE experiment, J. Am. Chem. Soc. 119 (1997) 7867-7868.

[15] G. Grasso, T.M. De Swiet, J.J. Titman, Electronic structure of the polymer phase of CsC60: Refocused INADEQUATE experiments, J. Phys. Chem. B 106 (2002) 8676-8680.

[16] G. De Paëpe, N. Giraud, A. Lesage, P. Hodgkinson, A. Böckmann, L. Emsley, Transverse dephasing optimized solid-state NMR spectroscopy, J. Am. Chem. Soc. 125 (2003) 13938-13939.

[17] D. Sakellariou, S.P. Brown, A. Lesage, S. Hediger, M. Bardet, C. Meriles, A. Pines, L. Emsley, High-resolution NMR correlation spectra of disordered solids, J. Am. Chem. Soc. 125 (2003) 4376-4380.

[18] R.A. Olsen, J. Struppe, D.W. Elliott, R.J. Thomas, L.J. Mueller, Through-bond 13C-13C correlation at the natural abundance level: refining dynamic regions in the crystal structure of vitamin-D3 with solid-state NMR, J. Am. Chem. Soc. 125 (2003) 11784-11785.

[19] N. Henin, R. Graf, S.C. Christiansen, C. Gervais, R.C. Hayward, J. Eckert, B.F. Chmelka, Structure of a surfactant-templated silicate framework in the absence of 3D crystallinity, J. Am. Chem. Soc. 126 (2004) 9425-9432.

[20] G. De Paëpe, A. Lesage, S. Steuernagel, L. Emsley, Transverse dephasing optimised NMR spectroscopy in solids: Natural-abundance ${ }^{13} \mathrm{C}$ correlation spectra, ChemPhysChem. 5 (2004) 869-875.

[21] S. Cadars, A. Lesage, L. Emsley, Chemical shift correlations in disordered solids, J. Am. Chem. Soc. 127 (2005) 4466-4476.

[22] F. Fayon, G. Le Saout, L. Emsley, D. Massiot, Through-bond phosphorus-phosphorus connectivities in crystalline and disordered phosphates by solid-state NMR, Chem. Commun. (2002) 1702-1703. 
[23] F. Fayon, I.J. King, R.K. Harris, J.S.O. Evans, D. Massiot, Application of the throughbond correlation NMR experiment to the characterization of crystalline and disordered phosphates, C. R. Chim. 7 (2004) 351-361.

[24] M. Feike, C. Jäger, H.W. Spiess, Connectivities of coordination polyhedra in phosphate glasses from ${ }^{31} \mathrm{P}$ double-quantum NMR spectroscopy, J. Non-Cryst. Solids 223 (1998) 200206.

[25] R. Witter, P. Hartmann, J. Vogel, C. Jäger, Measurements of chain length distributions in calcium phosphate glasses using 2D ${ }^{31} \mathrm{P}$ double quantum NMR, Solid State NMR 13 (1998) 189-200.

[26] U. Friedrich, I. Schnell, D.E. Demco, H.W. Spiess, Triple-quantum NMR spectroscopy in dipolar solids, Chem. Phys. Letters 285 (1998) 49-58.

[27] M. Edén, M.H. Levitt, Excitation of carbon-13 triple quantum coherence in magic-anglespinning NMR, Chem. Phys. Letters 293 (1998) 173-179.

[28] M. Carravetta, J. Schmedt auf der Günne, M.H. Levitt, Enhanced triple-quantum excitation in ${ }^{13} \mathrm{C}$ magic-angle spinning NMR, J. Magn. Reson. 162 (2003) 443-453.

[29] A. Binkmann, M. Edén, Second order average Hamiltonian theory of symmetry-based pulse schemes in the nuclear magnetic resonance of rotating solids: Application to triplequantum dipolar recoupling, J. Chem. Phys. 120 (2004) 11726-11745.

[30] M. Edén, A. Binkmann, Triple-quantum dynamics in multiple-spin systems undergoing magic-angle spinning: Application to ${ }^{13} \mathrm{C}$ homonuclear correlation spectroscopy, J. Magn. Reson. 173 (2005) 259-279.

[31] J. Schmedt auf der Günne, J. Beck, W. Hoffbauer, P. Krieger-Beck, The structure of poly(carbonsuboxide) on the atomic scale: A solid-state NMR study, Chem. Eur. J. 11 (2005) 4429-4440.

[32] M.H. Levitt, R.R. Ernst, Multiple-quantum excitation and spin topology filtration in high-resolution NMR, J. Chem. Phys. 83 (1985) 3297-3310.

[33] L. Baunschweiler, G. Bodenhausen, R.R. Ernst, Analysis of networks of coupled spins by multiple-quantum NMR, Mol. Phys. 48 (1983) 535-560.

[34] R.R. Ernst, G. Bodenhausen, A. Wokaun, Principles of Nuclear Magnetic Resonance in One and Two Dimensions, Clarendon Press, Oxford, 1987.

[35] G. Metz, X.L. Wu, S.O. Smith, Ramped-amplitude cross polarization in magic-anglespinning NMR, J. Magn. Reson. Ser. A 110 (1994) 219-227.

[36] B.M. Fung, A.K. Khitrin, K. Ermolaev, An improved broadband decoupling sequence for liquid crystals and solids, J. Magn. Reson. 142 (2000) 97-101.

[37] D.J. States, R.A. Haberkorn, D.J. Ruben, A two-dimensional nuclear overhauser experiment with pure absorption phase in four quadrants, J. Magn. Reson. 48 (1982) 286-292.

[38] O.W. Sorensen, G.W. Eich, M.H. Levitt, G. Bodenhausen, R.R. Ernst, Product operator formalism for the description of NMR pulse experiments, Prog. NMR Spectrosc. 16 (1983) 163-192.

[39] M. Bak, J.T. Rasmussen, N.C. Nielsen, SIMPSON: A general simulation program for solid-state NMR spectroscopy, J. Magn. Reson. 147 (2000) 296-330.

[40] M.H. Levitt, M. Eden, Numerical simulation of periodic nuclear magnetic resonance problems: Fast calculation of carousel averages, Mol. Phys. 95 (1998) 879-890.

[41] A. Brinkmann, M. Eden, M.H. Levitt, Synchronous helical pulse sequences in magicangle spinning nuclear magnetic resonance: Double quantum recoupling of multiple-spin systems, J. Chem. Phys. 112 (2000) 8539-8554.

[42] L. Duma, W.C. Lai, M. Carravetta, L. Emsley, S.P. Brown, M.H. Levitt, Principles of spin-echo modulation by J-couplings in magic-angle-spinning solid-state NMR, ChemPhysChem. 5 (2004) 815-833. 
[43] F. Fayon, D. Massiot, M.H. Levitt, J.J. Titman, D.H. Gregory, L. Duma, L. Emsley, S.P. Brown, Through-space contributions to two-dimensional double-quantum $J$ correlation NMR spectra of magic-angle-spinning solids, J. Chem. Phys. 122 (2005) 194313.

[44] G. De Paëpe, A. Lesage, L. Emsley, The performance of phase modulated heteronuclear dipolar decoupling schemes in fast magic-angle-spinning nuclear magnetic resonance experiments, J. Chem. Phys. 119 (2003) 4833-4841.

[45] G. De Paëpe, P. Hodgkinson, L. Emsley, Improved heteronuclear decoupling schemes for solid-state magic angle spinning NMR by direct spectral optimization, Chem. Phys. Letters 376 (2003) 259-267.

[46] A.E. Bennett, C.M. Rienstra, M. Auger, K.V. Lakshmi, R.G. Griffin, Heteronuclear decoupling in rotating solids, J. Chem. Phys. 103 (1995) 6951-6958.

[47] T. Averbuch-Pouchot, A. Durif, Structure of lead tetrapolyphosphate, Acta Cryst. C43 (1987) 631-632.

[48] P.J. Grandinetti, J.H. Baltisberger, A. Llor, Y.K. Lee, U. Werner, M.A. Eastman, A. Pines, Pure-absorption-mode lineshapes and sensitivity in two-dimensional dynamic-angle spinning NMR, J. Magn. Reson. Ser. A 103 (1993) 72-81.

[49] D. Massiot, B. Touzo, D. Trumeau, J.P. Coutures, J. Virlet, P. Florian, P.J. Grandinetti, Two-dimensional magic-angle spinning isotropic reconstruction sequences for quadrupolar nuclei, Solid State NMR 6 1(996) 73-83.

[50] V. B. Cheng, H.H. Suzukawa, M. Wolfsberg, Investigations of a nonrandom numerical method for multidimensional integration, J. Chem. Phys. 59 (1973) 3992-3999. 


\section{Figures}
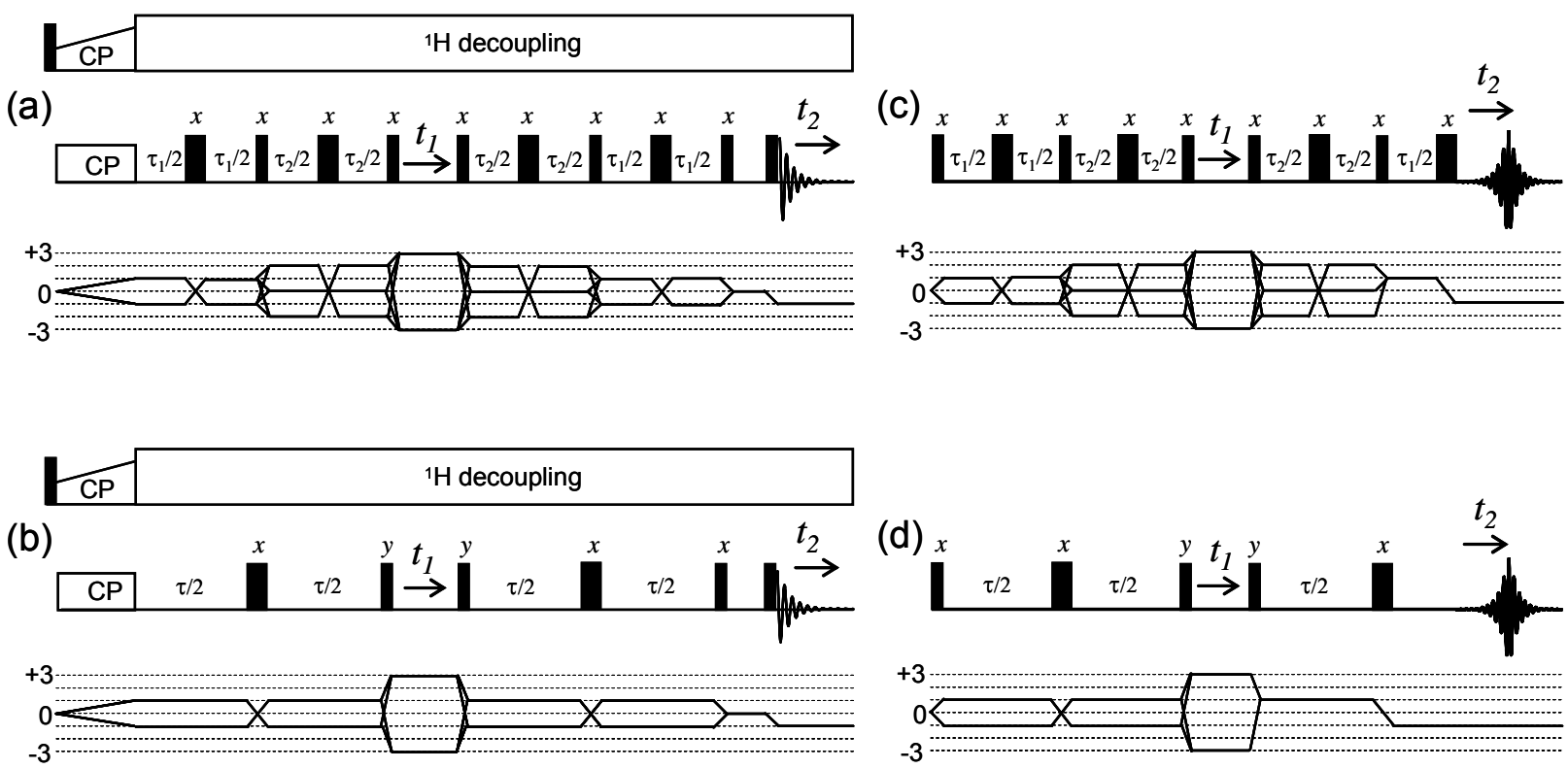

Figure 1: Pulse sequences used to record the TQ-SQ correlation spectra. The coherence transfer pathways assuming perfect pulses are indicated below each sequence. 

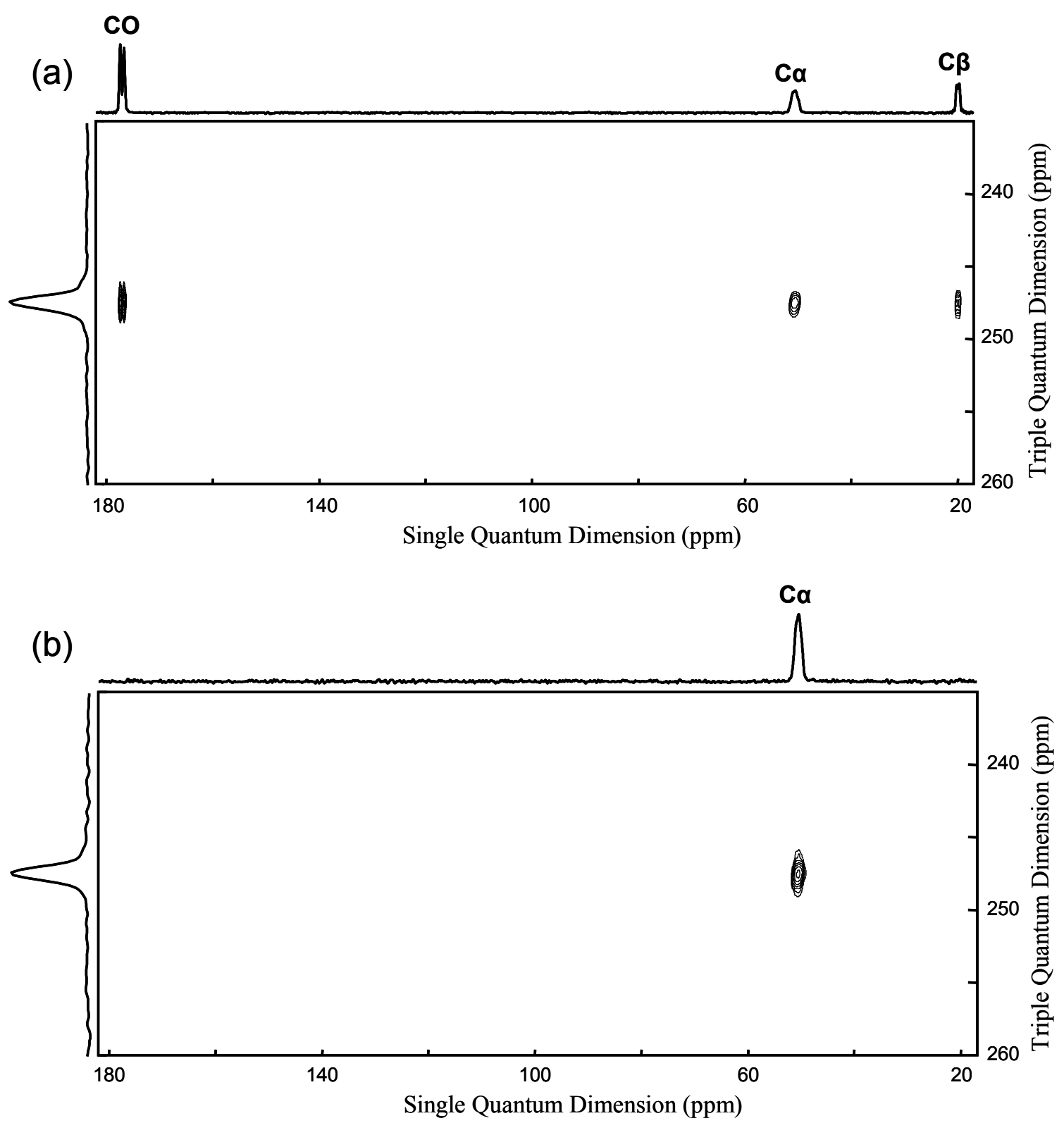

Figure 2: (a) Two dimensional TQ-SQ ${ }^{13} \mathrm{C}$ correlation spectrum of $\left[\mathrm{U}-{ }^{13} \mathrm{C}\right]$ L-alanine obtained using the pulse sequence in Fig. 1a with delays $\tau_{1}=\tau_{2}=9$ ms. $220 t_{1}$ increments with 48 transients each were collected using a recycle delay of $2 \mathrm{~s}$. The total experimental time was $7 \mathrm{~h}$ 15min. (b) 2D TQ-SQ correlation spectrum recorded using the pulse scheme in Fig. 1b with a delay $\tau$ of $10 \mathrm{~ms}$. $180 t_{1}$ increments with 48 transients each were collected using a recycle delay of $2 \mathrm{~s}$. The total experimental time was about $6 \mathrm{~h}$. In (a) and (b), 7 contours levels are plotted with a bottom contour at $6 \%$ and a multiplicative factor of 1.55 . The sum projections along the two dimensions are shown at the top and the left side of the $2 \mathrm{D}$ spectra. 
(a)

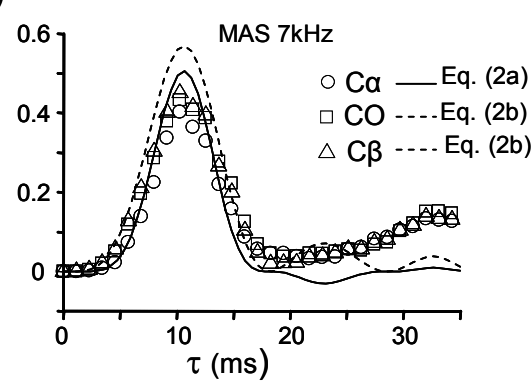

(b)

(c)
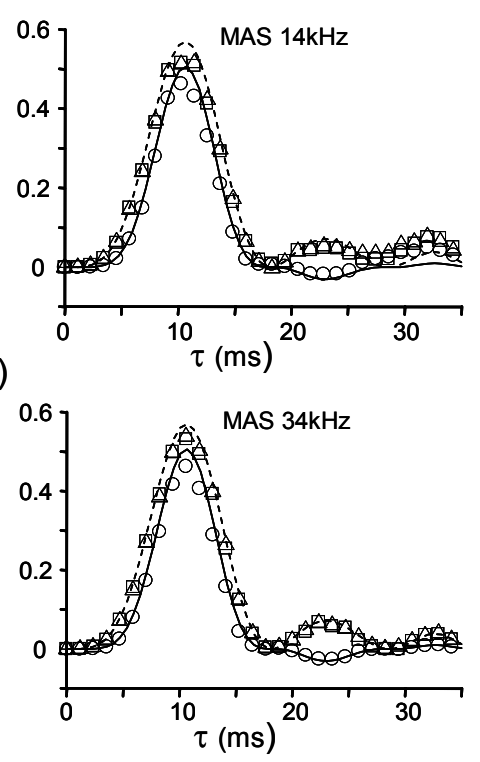

(d)

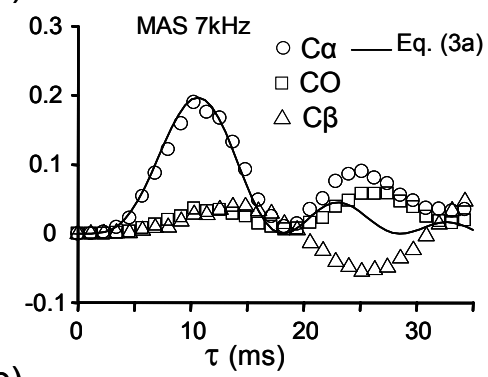

(e)
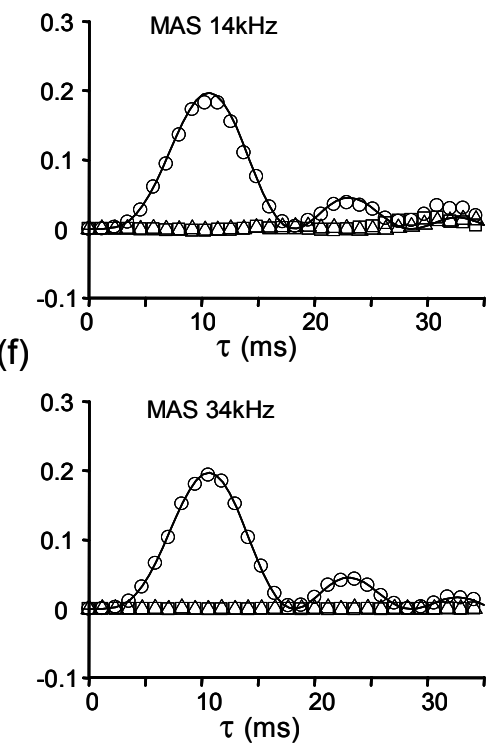

Figure 3: $(\mathrm{a}-\mathrm{e})$ Numerical simulations of the TQF efficiency for fully ${ }^{13} \mathrm{C}$-labelled L-alanine in a magnetic field of 7.0 T using the pulse sequences in Fig. 1a $(\mathrm{a}-\mathrm{c})$ and Fig. $1 \mathrm{~b}(\mathrm{~d}-\mathrm{f})$. Circle, triangle and square symbols correspond to the $\mathrm{C}^{\alpha}, \mathrm{C}^{\beta}$ and $\mathrm{CO}$ resonances, respectively. The spinning frequencies are $(\mathrm{a}, \mathrm{d}) 7$, (b, e) 14 and (c, f) $34 \mathrm{kHz}$. The simulations were performed with SIMPSON [39] using the parameters given in [40,41] and neglecting relaxation effects. Powder averaging was performed using $615\left\{\alpha_{\mathrm{M}}, \beta_{\mathrm{M}}\right\}$ molecular orientational angles, chosen according to the ZCW scheme [50], and 10 values for the $\gamma_{\mathrm{M}}$ angle. The curves indicate the efficiencies expected from standard product operator algebra [38] for a liquid-like J-coupling Hamiltionan in the weak coupling approximation. In $(\mathrm{a}-\mathrm{c})$, the curves correspond to the Eq. [2a] (solid line) and to the Eq. [2b] (dashed line) and in (d f), the curve correspond to the Eq. [3a] using $J_{\mathrm{CO}-\mathrm{C} \alpha}=55 \mathrm{~Hz}$ and $J_{\mathrm{C} \alpha-\mathrm{C} \beta}=35 \mathrm{~Hz}[40,41]$. 
(a)

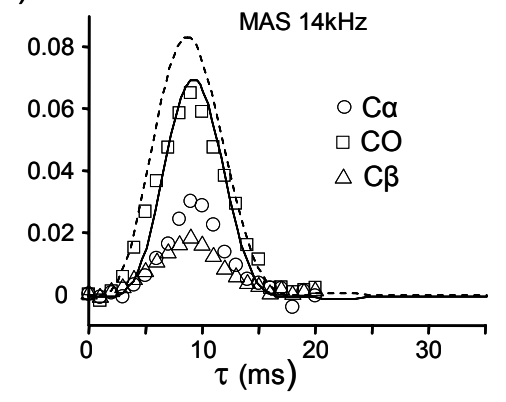

(b)

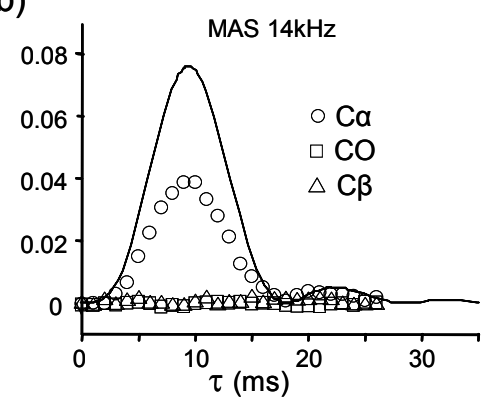

Figure 4: $(\mathrm{a}-\mathrm{b})$ Experimental TQF efficiencies obtained for fully ${ }^{13} \mathrm{C}$-labelled L-alanine, for a spinning frequency of $14 \mathrm{kHz}$ in a magnetic field of $7.0 \mathrm{~T}$, using the sequences in Fig. 1a and Fig. $1 \mathrm{~b}$, respectively. Circle, triangle and square symbols correspond to the $\mathrm{C}^{\alpha}, \mathrm{C}^{\beta}$ and $\mathrm{CO}$ resonances, respectively. The curves correspond to the equations [2a-b] and [3a] including damping by single exponential decay function with a phenomenological time constant $\mathrm{T}$ of 20 ms. 

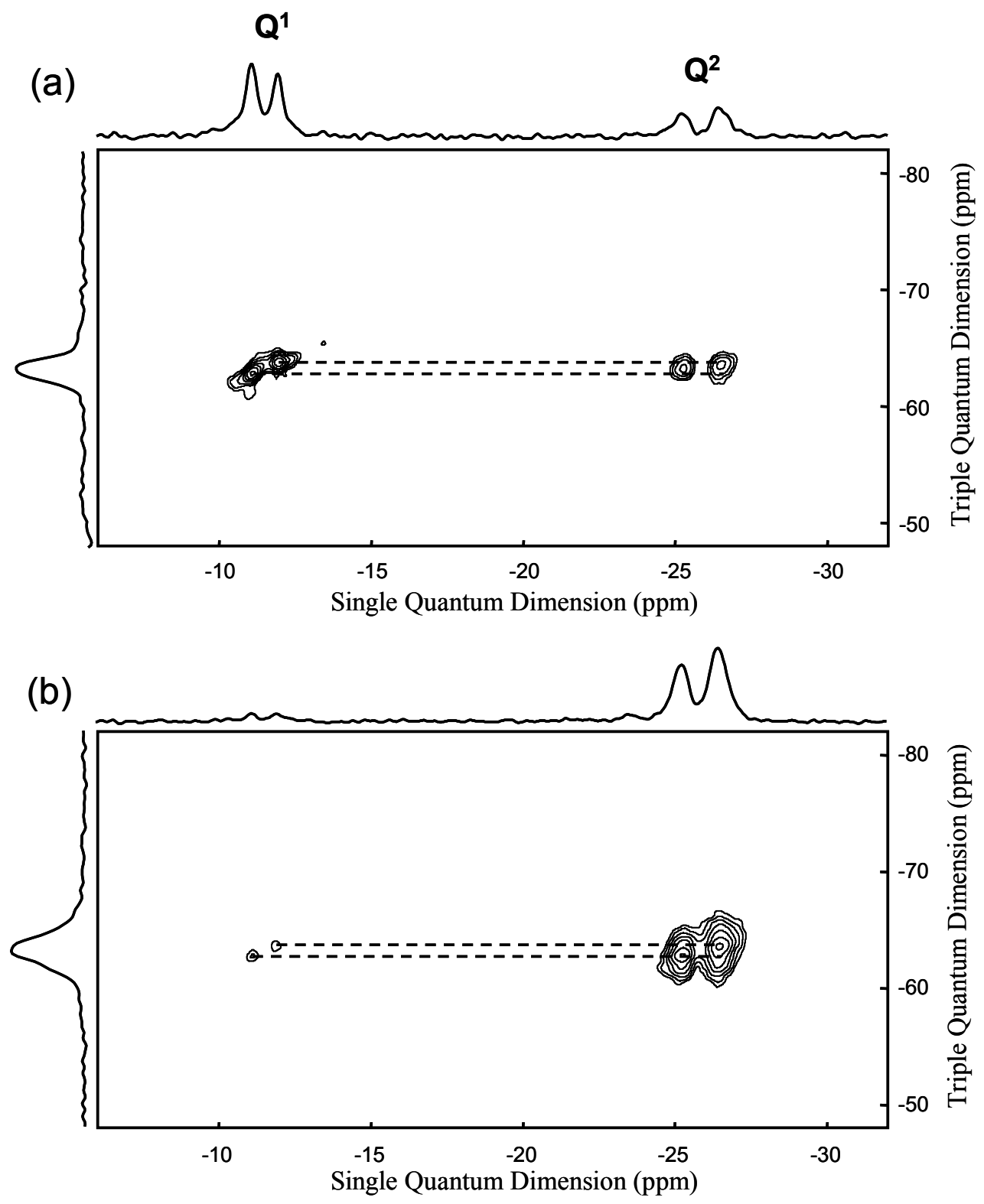

Figure 5: Two dimensional TQ-SQ ${ }^{31} \mathrm{P}$ correlation spectra of crystalline $\mathrm{Pb}_{3} \mathrm{P}_{4} \mathrm{O}_{13}$ obtained at a spinning frequency of $14 \mathrm{kHz}$, (a) using the sequence in Fig. 1a and (b) the sequence of Fig. 1b. 7 contours levels are plotted with a bottom contour at $8 \%$ and a multiplicative factor of 1.5. The sum projections along the two dimensions are shown at the top and the left side of the $2 \mathrm{D}$ spectra. The spectrum in (a) was recorded with delays $\tau_{1}=16 \mathrm{~ms}$ and $\tau_{2}=10 \mathrm{~ms}$ in the two consecutive spin-echo periods used both for the TQ excitation and reconversion. The spectrum in (b) was acquired with a delay $\tau$ of $16 \mathrm{~ms}$. For both spectra, $128 t_{1}$ increments with 48 transients each were collected. The recycle delay was set to $18 \mathrm{~s}$ with a presaturation sequence to ensure equivalent condition for each transient. The total experimental time was $32 \mathrm{~h}$. 

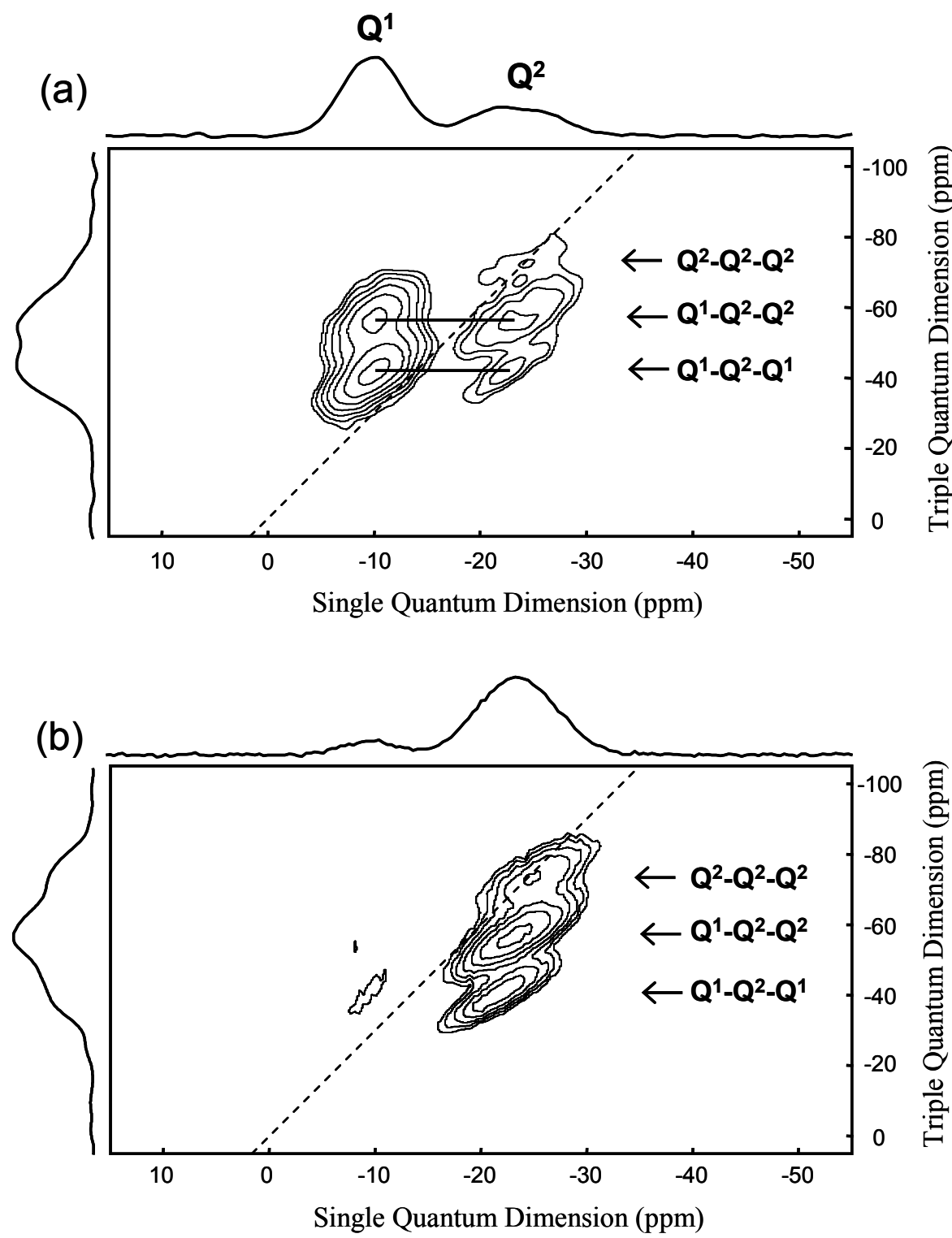

Figure 6: (a) Two dimensional TQ-SQ ${ }^{31} \mathrm{P}$ correlation spectra of the $(\mathrm{PbO})_{0.61}\left(\mathrm{P}_{2} \mathrm{O}_{5}\right)_{0.39}$ glass obtained at a spinning frequency of $14 \mathrm{kHz}$ using the sequence in Fig. 1a. The spectrum was recorded with delays $\tau_{1}=14$ and $\tau_{2}=12 \mathrm{~ms}$ in the two consecutive spin-echo periods used for both the TQ excitation and reconversion. $32 t_{1}$ increments with 264 transients each were collected using a recycle delay of $15 \mathrm{~s}$, corresponding to a total experimental time of about 38 h. (b) 2D TQ-SQ correlation spectra obtained at a spinning frequency of $14 \mathrm{kHz}$ using the sequence in Fig. 1b. The delay $\tau$ was set to $19 \mathrm{~ms} .32 t_{1}$ increments with 168 transients each were collected using a recycle delay of $15 \mathrm{~s}$, corresponding to a total experimental time of about 24 h. 7 contour levels are plotted in (a) and (b) with a bottom contour at $10 \%$ and a multiplicative factor of 1.4. The sum projections along the two dimensions are shown at the top and the left side of the 2D spectra. 


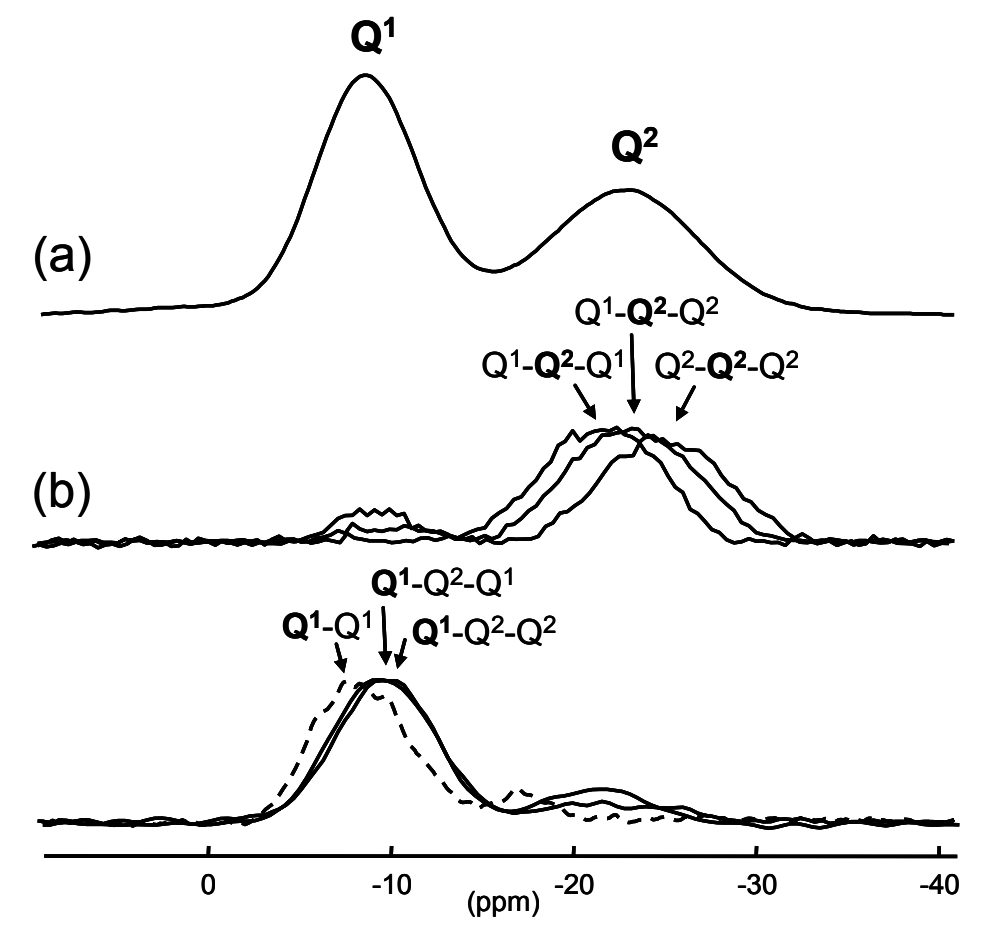

Figure 7: (a) Isotropic region of the ${ }^{31} \mathrm{P} 1 \mathrm{D}$ MAS spectra of the $(\mathrm{PbO})_{0.61}\left(\mathrm{P}_{2} \mathrm{O}_{5}\right)_{0.39}$ glass. (b) Projections (scaled with an arbitrary factor) of the different spin-triplet correlation peaks along the SQ dimension of the TQ-SQ spectra shown in Fig. 5a and 5b. The projection of the $\mathrm{Q}^{1}-\mathrm{Q}^{1}$ correlation peak along the SQ dimension of a DQ-SQ spectrum obtained with the refocused INADEQUATE sequence is also shown as a dashed line [23]. 